\title{
An introduction to sadharanikaran model of communication
}

- Nirmala Mani Adhikary

This article describes sadharanikaran model of communication (SMC) and outlines its fundamentals. The article initially discusses the concept of 'sadharanikaran' as conceived in Hindu poetics aknowledging its relevance for the modern discipline of communication. And, it also presents an account of the background upon which the model was developed and proposed. The descriptive part of the article is primarily indebted to Natyashastra ${ }^{1}$ and Vakyapadiya ${ }^{2}$.

\section{Sadharanikaran and communication}

Sadharanikaran, drawing from classical Hindu poetics, has been introduced into the modern communication discipline, essentially due to its qualification in this regard. The term has been an extensively used concept in Sanskrit and allied literary circles for explaining poetics, aesthetics and drama. It is rooted in Natyashastra of Bharata. There have been attempts to extend its history up to the Vedic period (Adhikary, 2007a, p. 108), but scholars widely believe that Bhattanayaka introduced the concept of sadharanikaran (Vatsyayan, 1996, p. 146). He is credited for use of the term in his commentary on Natyashastra to explain the concept of rasa. ${ }^{3}$

The term sadharanikaran is derived from the Sanskrit word sadharan; and has been translated into English as "generalized

\footnotetext{
${ }^{1}$ For further discussion on Natyashastra, see: Nagar \& Joshi, 2005; Pande, 1991; Tarlekar, 1999; Vatsyayan, 1996.

${ }^{2}$ For further discussion on Vakyapadiya, see: Abhyankar \& Limaye, 1965; Patnaik, 1994; Sastri, 1991.

${ }^{3}$ For further discussion on rasa, see: Masson \& Patwardhan, 1970; Mishra, 1964; and other entries in the reference section related to Natyashastra. It is to note: "The concept of rasa cannot be understood fully without taking into account the larger background of the speculative thought of the Upanisads" (Vatsyayan, 1996, p. 56).
}

Bodhi, 3 (1), 69-91. ISSN 2091-0479. (C) 2009 Kathmandu University 
presentation" (Vedantatirtha, 1936, p. 35), "simplification" (Yadava, 1998, p. 187), and "universalization" (Dissanayake, 2006, p. 4). This concept is bound with another concept, sahridayata, that is, a state of common orientation, commonality or oneness. Sadharanikaran is the attainment of sahridayata by communicating parties.

When senders and receivers accomplish the process of sadharanikaran, they attain saharidayata and become sahridayas. In other words, communicating parties, for e.g., actor and audience, become sahridayas when they are engaged in a communicative relation leading to the attainment saharidayata; and it is in this stage sadharanikaran is accomplished. Thus the essence of sadharanikaran is to achieve commonness or oneness among the people.

In this light, the Latin word 'communis' and its modern English version 'communication' come close to sadharanikaran (Adhikary, 2003, pp. 82-83, 2004, pp. 30-33, 2007a, pp. 107109; Tewari, 1980, 1992; Yadava, 1987, 1998). However, as Yadava puts it, "the characteristics and the philosophy behind Sadharanikaran are somewhat different from communication concept as developed in the Western societies" (1998, p. 187). ${ }^{4}$

\section{From the theory to the model}

The history of studying communication from Hindu (or 'Indian') perspective goes back to at least five decades ago (Majumdar, 1958). Various efforts have been made in order to understand, discuss and/or theorize communication from Asian perspectives, sometimes particularly from Hindu perspective (Adhikary, 2003, 2004, 2007a, 2007b, 2007c, 2007d, 2008b; Babbili, 2001; Davis, 1988; Dhole, 2006; Dissanayake, 1981, 1982a, 1982b, 1983, 1986, 1987, 1988a, 1988b, 2006; Gangal \& Hosterman, 1982; Gumperz, 1964; Gunaratne, 1991; Jain \&

\footnotetext{
${ }^{4}$ For comparative study, see: Adhikary, 2003, pp. 97-110; 2007a, pp. 117-119; 2007b; 2008b.
}

Bodhi, 3 (1), 69-91. ISSN 2091-0479. (C) 2009 Kathmandu University 
Matukumalli, 1996; Jayaweera, 1988; Kirkwood, 1987, 1989, 1990, 1997; Kumar, 2005a, 2005b; Mohan, 1992; Oliver, 1971; Rahim, 1987; Saral, 1983; Sitaram, 2004; Tewari, 1980, 1992; Thirumalai, 2003, 2004, 2006; Yadava, 1979, 1982, 1987, 1998). It is not possible here to present a survey of these works. But it is to mention that most of these works identify themselves as a part of searching the 'Asian' communication perspective. $^{5}$

It has become customary to mention Sadharanikaran as Hindu/Indian theory of communication. ${ }^{6}$ And, numerous academic institutions have already incorporated sadharanikaran as the Hindu/Indian theory of communication in their curricula.

In the case of Nepal, the researcher has been acknowledged as the initiator of the discourse regarding Hindu/Nepali perspective on communication (Khanal, 2008, pp. 21-22; Pant, 2009, pp. 84-86. Also see: Adhikary, 2009, p. 296). Firstly, an article was published highlighting the need to explore native Nepali perspective while studying communication, and tracing some sources in this regard (Adhikary, 2003, January 13). Then, research was conducted for an M. A. thesis (Adhikary, 2003).

The research (Adhikary, 2003), drawing on Bharata Muni's Natyashastra and Bhartrihari's Vakyapadiya, illustrates that communication process as envisioned in Vedic Hinduism can be represented by the concept of sadharanikaran. And, a unique communication model - sadharanikaran model of

\footnotetext{
${ }^{5}$ For further discussion on the 'Asian' perspective on communication, see: Chen \& Miike, 2006; Dissanayake, 2006; Gordon, 2007; Miike, 2007, 2009; Miike \& Chen, 2006; Xiaoge, 2000.

${ }^{6}$ There are authors, including I. P. Tewari and J. S. Yadava, who prefer to claim the Sadharanikaran theory as "Indian" communication theory. But, in my view, terming Sadharanikaran as the "Indian" theory is politically incorrect. Replacing it by 'Hindu' would be broader approach. Kumar (2005b) has termed it "Indian/Hindu" theory.
}

Bodhi, 3 (1), 69-91. ISSN 2091-0479. (C) 2009 Kathmandu University 
communication (SMC) - has been developed and presented through that research which was the first ever model of communication in diagrammatic form proposed from the East. "The model," Khanal (2008) says, "gives new dimension to study on communication from Hindu perspective" (p. 21). Pant (2009, November 24, p.4) says, "The exploration of such a model based on the Eastern perspective will undoubtedly contribute to the development of new communication theories."

A point to note at this juncture is the SMC is not the only possible model of communication from Hindu perspective. Rather, there is scope for other communication models from Hindu perspective:

With vast diversities of cultures and philosophies within the Hindu society, it is just one of many models that could be developed. Many theories and models of communication would come out if communication discipline has enthusiasm of encountering different Hindu philosophical traditions. (Adhikary, 2008b, p. 286)

Till the date, the Sadharanikaran model remains only one of such models that could visualize Hindu perspective on communication.

\section{The Sadharanikaran model}

Proposed by Adhikary (2003) the Sadharanikaran model illustrates how the communicating parties interact in a system (i.e., the process of sadharanikaran) for the attainment saharidayata (commonness or oneness). The model "offers an explanation of how successful communication is possible in Hindu society where complex hierarchies of castes, languages, cultures and religious practices are prevalent" (Adhikary, 2008a, p. 67). Observing the model as a representation of communication process as envisioned in Hindu perspective, Pant (2009) remarks, "It is systematic description in diagrammatic form of a process of attaining commonness or oneness among people" (pp. 84-85).

Bodhi, 3 (1), 69-91. ISSN 2091-0479. (C) 2009 Kathmandu University 


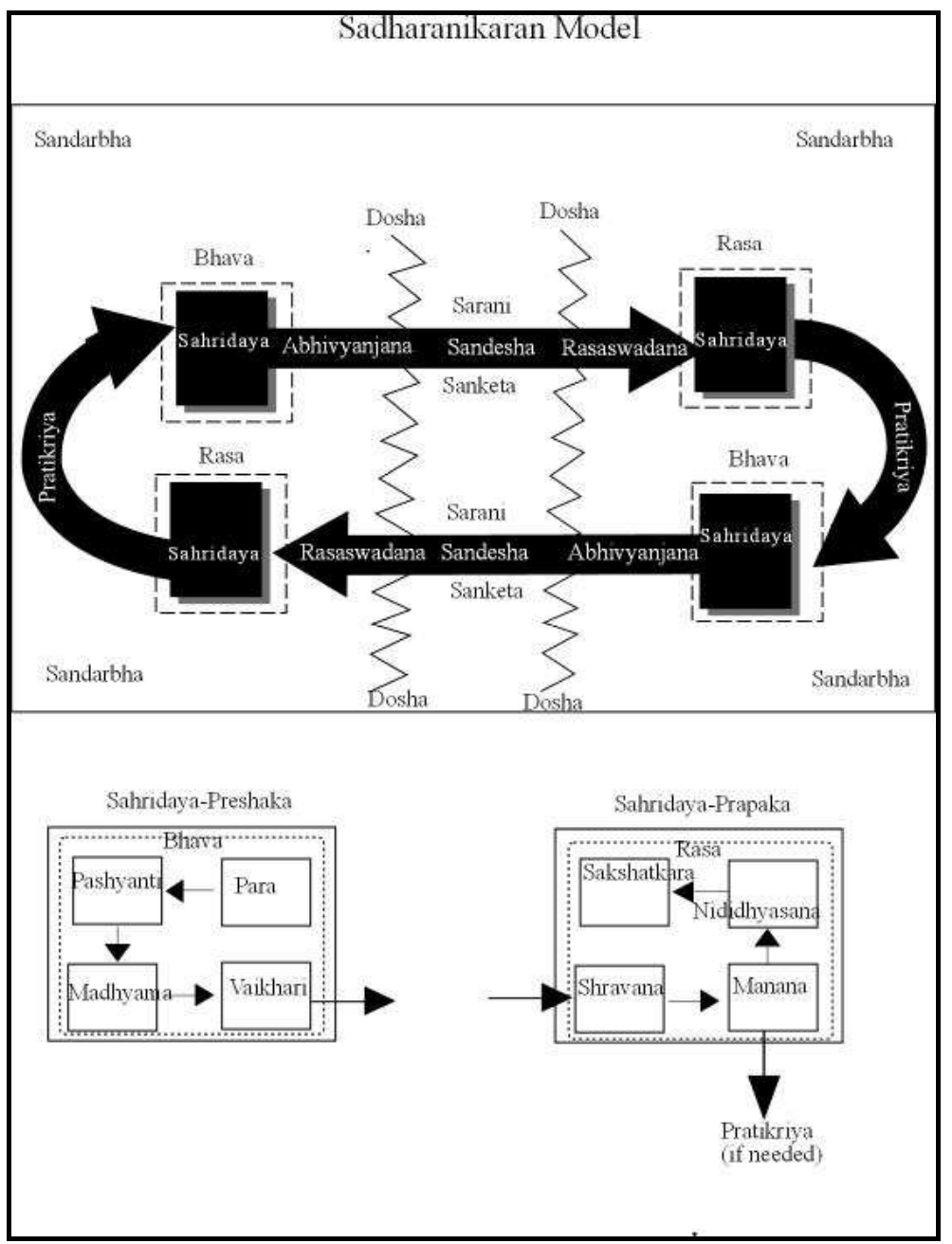

Fig. Sadharanikaran model of communication (SMC)

The model comprises the following elements:

1. Sahridayas (Preshaka, i.e., sender, and Prapaka, i.e., receiver)

2. Bhava (Moods or emotions)

3. Abhivyanjana (Expression or encoding)

Bodhi, 3 (1), 69-91. ISSN 2091-0479. (C) 2009 Kathmandu University 
4. Sandesha (Message or information)

5. Sarani (Channel)

6. Rasaswadana (Firstly receiving, decoding and interpreting the message and finally achieving the rasa)

7. Doshas (Noises)

8. Sandarbha (Context)

9. Pratikriya (Process of feedback)

Sadharanikaran as a concept/theory should not be confused with the sadharanikaran model. The former, which is one of the significant theories in Sanskrit poetics, has its root in Natyashastra and is identified with Bhattanayaka. Whereas, latter refers to a model of communication which draws on the classical concept/theory of sadharanikaran along with other resources in order to visualize Hindu perspectives on communication.

Sahridayata is the core concept upon which the meaning of sadharanikaran resides. It is the state of common orientation, commonality or oneness. Senders and receivers become sahridayas with the completion of the process of Sadharanikaran. In a society that has asymmetrical relationships between communication parties, it is only due to sahridayata the two-way communication and mutual understanding is possible. Thus, communicating parties can attain sahridayata irrespective of complex hierarchies of castes, languages, cultures and religious practices, and the communication process qualifies to be considered as sadharanikaran.

Sadharanikaran, as the communication process, consists of sahridayas as the communicating parties. As a 'technical term', the word refers to people with a capacity to send and receive messages. They are the parties engaged in communication, and capable of identifying each other as sender and receiver of the process. A sahridaya is a person in such state of emotional intensity which is coequal or parallel to that of other(s) engaged in communication. Ideally, the term refers such persons who are

Bodhi, 3 (1), 69-91. ISSN 2091-0479. (C) 2009 Kathmandu University 
not only engaged in communication but also have attained a special state: sahridayata. As such, a sahridaya is one who has attained sahridayata. Thus, sadharanikaran is the process of attaining sahridayata, and, the sadharanikaran model illustrates the process.

If communication is taken as a step-by-step process, which is just for the shake of easy understanding, the sahridaya-preshaka (simply, the sender), who has bhavas (moods or emotions or thoughts or ideas) in mind, is the initiator of the process. The sahridaya-sender has to pass the process of abhivyanjana for expressing those bhavas in perceivable form. It is the sahridayaprapaka (simply, the receiver) with whom the bhavas are to be shared. He or she has to pass the process of rasaswadana.

The position of the sahridaya-sender and the sahridaya-receiver is not static. Both parties are engaged in the processes of abhivyanjana and rasaswadana. When sadharanikaran is successful, universalization or commonness of experience takes place. In Natyashastra itself, Bharata Muni has emphasized on a total communication effort including the use of the words as well as limbs, gestures, and body language along with the physical context in order to ensure communication at its best.

As evident from the figure, the sender inherits bhava. Human being in his/her essential characteristics is a bundle of bhavas that constitutes his/her being and form part of his/her total consciousness. It is due to the bhavas that human being aims engaging in communication or sadharanikaran process. If there were no bhavas and human beings had no desire to share their bhavas with others, there would be no need of communication. The bhavas have been categorized into different types, such as sthayee bhavas (permanently dominant), vyabhichari or

\footnotetext{
${ }^{7}$ Bharata Muni has described eight sthayee bhavas: Rati (Love), Hasa (Merriment), Shoka (Sorrow), Krodha (Fury), Utsaha (Enthusiasm), Bhaya (Terror), Jugupsa (Disgust) and Vismaya (Astonishment).
}

Bodhi, 3 (1), 69-91. ISSN 2091-0479. (C) 2009 Kathmandu University 
sanchari bhavas (moving or transitory) ${ }^{8}$ and satvika or sattvaja bhavas (originating from the mind, temperamental). Corresponding to bhavas, human inherits rasas, which are to be discussed later.

Abhivyanjana refers to the activities that a source goes to translate bhavas into a form that may be perceived by the senses. It can be understood as expression or encoding in English. The guiding principle while encoding in sadharanikaran is simplification. Simplification is the essential dimension here. In the communiation process; the complex concepts and ideas are simplified by the speaker (source) with illustrations and idioms appropriate for the understanding of the listeners (receiver of the messages). This approach makes communication a dynamic, flexible, practical and effective instrument of social relationship and control.

Sanketa (code) is an integral part of abhivyanjana. A kind of code is a must to let the bhavas manifested. Codes are symbols that are organized in accordance with specific rules. For example, the language is a code. The sender encodes the bhava in a code. For communication to be successful, both the sender and receiver must understand the code being used.

${ }^{8}$ According to Bharata Muni, there are 33 vyabhichari or sanchari bhavas. They are: Nirveda (Despondency), Glani (Weakness), Shanka (Suspicious), Asuya (Envy), Mada (Inebriation), Shrama (Exhaustion), Alasya (Lethargy), Dainya (Depression), Chinta (Anxiety), Moha (Delusion), Smriti (Recollection), Dhriti (Fortitude), Vrida (Bashfulness), Chapalata (Inconstancy), Harsha (Joy), Avega (Excitement), Jadata (Stupefaction), Garva (Arrogance), Visada (Despair), Autsukya (Impatient curiosity), Nidra (Sleep), Apasmara (Loss of memory), Swapna (Dreaming), Prabodha (Wakening), Amarsha (Indignation), Avahitta (Dissimulation), Ugrata (Cruelty), Mati (Self-assurance), Vyadhi (Sickness), Unmada (Madness), Marana (Death), Trasa (Fright) and Vitarka (Deliberation). ${ }_{9}^{9}$ According to Bharata Muni, there are eight sattwik bhavas. They are: Stambha (Paralysis), Sweda (Sweat), Romancha (Horripilation), Swarasada (Feebleness in the voice), Vepathu (Trembling), Vaivarnya (Change of color), Asru (Shedding tears) and Pralaya (Loss of sense).

Bodhi, 3 (1), 69-91. ISSN 2091-0479. (C) 2009 Kathmandu University 
Abhivyanjana may be in verbal or non-verbal code, and both codes may be used simultaneously.

In case of verbal abhivyanjana, words/languages are used as the code. The process of abhivyanjana has been shown consisting of four stages in the figure. It owes to concept of language as a code as conceived in Sanskrit linguistics and Hindu philosophy of language. Here, there are four levels or stages of language from which the word (shabda or vak) passes: para, pashyanti, madhyama and finally the uttered word vaikhari. ${ }^{10}$ In other words, any bhava can be perceived externally only when it comes to the vaikhari level.

Vaikhari vak is the manifested form of the word. It is in the most external and differentiated level. Here, the word is commonly uttered by the speaker and heard by the hearer. Before being uttered, the word or vak resides in mind or intellect, and is named as madhyama. It is the idea, or series of words, as conceived by the mind after hearing or before being spoken out. It may be thought of as inward speech. The next and the innermost stage, according to Bhartrihari, is the pashyanti vak. Pashyanti is the vak at the level of direct intuition, and can be understood through experience. Here, humans get the direct experience of the vakya-sphota, as Bhartrihari says. In Vakyapadiya and its Vritti commentary, this term 'para' is not used to denote a fourth level of speech. Bhartrihari says that speech is threefold; and he treats the third level of pasyanti as ultimate. It is later on in the tradition that the name 'para' appears, referring to a fourth level. Para vak is the Shabda Brahman.

In case of the non-verbal abhivyanjana, the communicator has wide alternatives of code to use. Bharata Muni has described

${ }^{10}$ Rigved says: "Chatvari vak parimita padani" (1.164.45). But, Bhartrihari himself has described three levels of speech: Pashyanti, Madhyama and Vaikhari.

("vaikharya madhyamayas cha pasyantyas chai 'tad adbutam aneka-tirtha-bhedayas trayya vachah param padam")

Bodhi, 3 (1), 69-91. ISSN 2091-0479. (C) 2009 Kathmandu University 
wide alternatives of abhivyanjana including gestures of limbs, representation through make up and temperamental expressions as well as various sounds. Some of them entirely deal the nonverbal aspect while others consists some forms of it. Under angika abhinaya, he has directed as many as 122 types of karmas (performing arts or abhinayas) by using six angas (limb) and six upangas (ancillary limb) of human body (Adhikary, 2007d).

According to Bharata Muni, each bhava is associated with both sensory experience and aesthetic emotion. He considers the bhavas as representation of mental state. They do not come from outside, rather they always remain within the mind. However, they are not always in the awaken state. They have to be or are stirred by external factors called vibhava that is a stimulus or determinant such as song, a bird, a picture, etc. Vibhava may be alamvana or uddipana. When a snake is seen and certain kind of emotion is stirred it is called alamvana vibhava. The sense of fear would increase due to the movement of snake's tongue and such stimulus contributing for the increase in vibhava is called uddipana vibhava.

After the bhavas are stimulated due to vibhava, the anubhava is certain, that is, some sort of manifestation such as glance, lifting of eye, smile, etc. Anubhavas may be internal or external. Bharata Muni has identified three external and eight internal anubhavas. The bhavas need some sort of code for their manifestation. For this, they have to pass through the process of abhivyanjana.

With the completion of the process of abhivyanjana, bhavas are manifested as sandesha. In other words, sandesha is outcome of the abhivyanjana process. A message is the manifestation of the bhava into a form (code) that is perceivable by the senses. It is the information that the sender wants to pass on to the receiver. It is the actual physical product that the source encodes, and which the receiver's sensory organs can detect. In other words, it is the coded idea that conveys meaning. Just doing 'namaste'

Bodhi, 3 (1), 69-91. ISSN 2091-0479. (C) 2009 Kathmandu University 
to explaining the 'Adwaita vedanta' philosophy all are messages.

Messages may be in verbal or non-verbal depending upon the encoding done by the sender. In case of Natyashastra, messages have been distinguished as angika (gestures of limbs), vachika (verbal display), aharya (representation through make up) and sattvika (temperamental), each consisting different types. For instance, angika is seen consisting of three types ${ }^{11}$, where as vachika has twelve forms ${ }^{12}$.

For transmission of sandesha, there needs sarani (channel or medium), which is the means through which sandesha travels across space. The message sent by the source or sender cannot reach the receiver without the channel or medium. The channels may be natural corresponding to biological nature of human being such as: auditory (hearing), tactile (touching), visual (seeing), olfactory (smelling) and taste (tasting through the taste buds on the tongue) channels. The channels may be artifactual such as paintings, sculptures, letters, etc. These two types of channels are extensively described in Natyashastra. The channels may be mechanical such as telephones, radio, TV, computers and so on. It is yet to study whether the text inherits concepts of some kind of mechanincal channels.

Hindu perspective on communication would not be completed unless both manas (mind) and sharira (human body) are understood as sarani. At least, it is so for spiritual dimension of the process. The manas is considered as the sixth indriya (sensory organ) in Hindu belief. It is the vibhu (master) of five senses. However, it is not the final authority in this regard. Its

\footnotetext{
${ }^{11}$ Sharira (bodily), Mukhaja (facial), Chestakrita (brought about by the movements).

${ }^{12}$ Alapa (Accosting), Pralapa (Prattling), Vilapa (Lamentation), Anulapa (Repeated utterances), Samlapa (Dialogue), Apalapa (Change of words), Sandesha (Notice), Atidesha (Agreement), Nirdesha (Command direction), Vyapadesha (Pretext), Upadesha (Instruction, Advice) and Apadesha (Statement).
}

Bodhi, 3 (1), 69-91. ISSN 2091-0479. (C) 2009 Kathmandu University 
vibhu is the atman. The mental life is not the aspiration, rather the assertion of a higher than the mental life is the whole foundation of Hindu philosophy. In fact, the human life is a means, not the end. In Hindu belief, the bodily self is not the ultimate truth though it is essential for the worldly existence. The body is only a temporary abode of atman, and it is an instrument or means used by the atman. In other words, sharira is a sarani by using which atman has to attain moksha.

With the proper use of various saranis as discussed above, the sender successfully sends the message toward the receiver. As abhivyanjana was crucial for the sender, so is rasaswadana for the receiver. The term as used here should be understood as a 'technical term' carrying a wide range of meaning. Its range is from receiving the message to decoding and interpreting the message and finally to the attainment the rasa. Orthodox Hindu uses of the term refer to the state of rasa experience by the sahridaya-receiver. In case of casual human communication, rasaswadana is said to be successful if the receiver shares the message as intended by the sender. However, the spiritual dimension goes beyond.

Not all communication result in the attainment of rasa in its ideal form. Rasa is the essence or aesthetic enjoyment. Bharata Muni terms this as rasa because it is worthy of being tested (relished). There is unique corresponding rasa to each bhava. ${ }^{13}$ According to Bharata Muni, the combination of vibhavas and anubhavas together with vyabhichari bhavas produce rasa. It is the sthayee bhava that leads to rasa. What happens is the sthayee bhava is stimulated by the vibhava in the mind and is heightened by anubhava and sanchari bhava, and the mind would be highly receptive to the rasa experience in this state.

\footnotetext{
${ }^{13}$ Bharata Muni has described eight rasas: Sringara (the erotic), Hasya (Humorous), Karuna (Pathos), Raudra (Impetous anger), Vira (Heroic), Bhayanaka (Terrific), Bibhatsa (the odious) and Adbhuta (the mysterious).
}

Bodhi, 3 (1), 69-91. ISSN 2091-0479. (C) 2009 Kathmandu University 
The issue how the meaning of a message is achieved has been much debated by scholars and philosophers. For instance, there are debates regarding the unit of meaning. For instance, some regard the words as the unit of meaning in verbal communication, where as Bhartrihari considers the total sentence as the unit of meaning. Even if a word is taken as the unit of meaning there are diverse views regarding what sort of entity is signified by the word.

As shown in the figure, the four levels of word discussed in case of abhivyanjana have corresponding levels while attempting rasaswadana. Where as shravana corresponds to vaikhari, so do manana, nididhyasana and sakshatkara with madhyama, pashyanti and para respectively. Not all people engaged in communication would be going through all these stages of abhivyanjana and rasaswadana. Sadharanikaran (communication) as social and mental activity would require just vaikhari and madhyama in the part of sender and shravana and manana in the part of receiver. But, spiritual dimension of the process would require further levels too. In other words, not all communicating parties would be attaining rasaswadana in its ideal form. Rather, it can be experienced only by the sahridayas in the ideal sense of the term.

Bharat Muni describes sadharanikaran as that point in the climax of a drama when the audience becomes one with the actor who lives an experience through his/her acting on stage and starts simultaneously reliving the same experience. The process has been described as rasaswadana. When sadharanikaran happens, sharing or commonness of experience takes place in full form. According to Bhattanayak, the essence of sadharanikaran is to achieve commonness or oneness among the people.

Two things are to be noted here. First, the vak (word or speech) in the continuum of para-sakshatkara is identified with the Brahman. Hence, sakshatkara is the state of experiencing the Self as the Brahman ("Aham Brahmasmi"). Second, the

Bodhi, 3 (1), 69-91. ISSN 2091-0479. (C) 2009 Kathmandu University 
Brahman is aslo considered as supreme rasa ("rasovaisah") and hence rasaswadana in its ultimate destination would be the rasaswadana of the Brahman. In this stage also there is unity of the Self and the Brahman. In either ways, sadharanikaran qualifies to be a means for moksha.

There is no such thing as perfect communication. There are continuous forces at work, doshas or noises, which tend to distort the message and lead to miscommunication. If we draw on Hindu poetics, the concept of rasa-bhanga (disruption in rasaswadana) is there. There may be many causes for this. For instance, a mismatch of meaning between sender (encoder) and receiver (decoder) of any message may occur. The model should be interpreted to include all of the noises, viz. semantic, mechanical, and environmental.

Bhartrihari has considered this possibility in Vakyapadiya that it is always possible to say conflicting things about what's in the texts and what they mean. To reduce uncertainty, some sacred text is made authentic, and a settled standpoint is established. ${ }^{14}$ This consideration leads us to the concept of sandarbha (context). The effectiveness of any message depends on the communication environment. Same message may have different meanings in different contexts.

The notion of context in the process of communication makes Hindu concept of communication even comprehensive. The

\footnotetext{
14 sarvo 'drista-phalan arthan agamat pratipadayate viparitam cha sarvatra sakyate vaktum agame tasmad agamam kinchit pramani-kritya vyavasthite tasmin ya kachid upapattir uchyamana pratipattav upodbalakatvam labhate

"It's commonly acknowledged that unseen effects may be achieved by chanting from the sacred texts. But it is always possible to say conflicting things about what's in the texts and what they mean. Therefore, some sacred text is made authentic, and a settled standpoint is established. There, according to whatever reason may determine to be fit and proper, confirmation is obtained."
}

Bodhi, 3 (1), 69-91. ISSN 2091-0479. (C) 2009 Kathmandu University 
importance of context is such that due to this factor meaning could be provided to the message even if the sender is not identified to the receiver. In other words, it is due to context, the intended meaning of any message can be ascertained without determining the actual intention in the mind of the speaker just by taking contextual factors into account. Thus due to the context a text can retain its 'objective' meaning.

Though both the sender and receiver of the message must be sahridayas Bhartrihari theorizes communication from the receiver's viewpoint. He has discussed how intended meaning is ensured though there is possibility of conflicting or diverging meanings of the same message. In brief, sandarbha (context), as discussed above, and intuition (pratibha), which is innate to the receiver, ensure proper understanding of any message.

Pratikriya refers to the responses of the receiver after receiving the message. It is the process of feedback, which allows the receiver to have active role in the communication process. Feedback can be understood as the same step-by-step process returning messages following exactly the same steps outlined above. Sadharanikaran process demands sahridayas undergoing the same kind of automated dynamism in taking the role of sender and receiver back and forth. Here, both the parties (the sahridaya-sender and the sahridaya-receiver) act as senders and receivers simultaneously. And, the process of encoding and decoding also occur simultaneously.

It is not that the feedback is always affirming. However, feedback makes the communication process ongoing. One of the unique features of the sadharanikaran model is that the provision of the feedback is not universal. The process of feedback will be there only when it is needed. It is needed certainly in physical or worldly forms of communication. In such form of communication, adequate feedback is sought. But after achieving the nididhyasana state, there is no need of feedback externally. In this state, the sahridayas become able to understand each other and experience the same obviously. In

Bodhi, 3 (1), 69-91. ISSN 2091-0479. (C) 2009 Kathmandu University 
the sakshatkara state, the sahridaya is already in the state of moksha, which is the ultimate goal of sadharanikaran process.

\section{Conclusion}

Communication, as conceived in Sadharanikaran model, is the process of attaining sahridayata, i.e., mutual understanding, commonality or oneness. It is only when the communicating parties attain sahridayata, and the communicating parties identify each other as sahridaya, communication process qualifies to be considered as sadharanikaran. Here, communication is sharing between communicating parties (sahridayas) with a view to not just persuade one or the other as such but to enjoy the very process of sharing. Furthermore, from the discussions in previous section, following conclusions are drawn on:

1. The structure of the model is non-linear. It incorporates the notion of two-way communication process resulting in mutual understanding of the communicating parties. Thus it is free from the limitations of linear models of communication.

2. The model illustrates how successful communication is possible in Hindu society where complex hierarchies of castes, languages, cultures and religious practices are prevalent. Sahridayata helps those communicating to pervade the unequal relationship prevailed in the society and the very process of communication is facilitated.

3. The interelationship between the communicating parties is of crucial importance in sadharanikaran. Here, not the cause of the relationship but the relationship itself is significant. For instance, the guru-shishya relationship is always considered sacred in itself. And, unlike in case of most communication theories and models from the West, this does not emphasize on

Bodhi, 3 (1), 69-91. ISSN 2091-0479. (C) 2009 Kathmandu University 
dominance by the sender. Rather, the model gives equal importance to both the communicating parties.

4. The model shows that abhivyanjana (encoding) and rasaswadana (decoding) are the fundamental activities in communication. In other words, they are decisive junctures in sadharanikaran (communication).

5. It shows that Hindu perspective on communication emphasizes more on internal or intrapersonal activity. For instance, both the processes of encoding and decoding consits of four-layer mechanism in its ideal form. As such, communication involves more experience within than objective rationality of the sensory organs.

6. With the provision of sandarbha (context), the model clarifies how meaning could be provided to the message even if the sender is not identified to the receiver. The intended meaning of any message can be ascertained due to the context, without determining the actual intention in the mind of the speaker just by taking contextual factors into account. Thus due to the context a text can retain its 'objective' meaning.

7. The scope of communication from Hindu perspective is broad. As envisioned in the model, communication is broader enough to deal with all of the three dimensions of life: adhibhautika (physical or mundane), adhidaivika (mental) and adhyatmika (spiritual). In social or worldly context, communication is such process by which, in ideal conditions, humans achieve sahridayata. In mental context, communication is the process of gaining true knowledge as well as similar mutual experience. But that is not the whole story; it has spiritual dimension too.

8. The goal of communication as envisioned in the model is certainly achieving commonness or mutual understanding. But, the goal would not be limited to just this extent. Just as Hinduism always emphasizes to achieve all of the purushartha chatustayas (i.e., four goals of life: artha, kama, dharma and moksha), the

Bodhi, 3 (1), 69-91. ISSN 2091-0479. (C) 2009 Kathmandu University 
model also conceives communication capable of attaining all these goals. Thus, the model is in perfect consonance with Hindu World View.

\section{References}

Abhyankar, K. V., \& Limaye, V. P. (Eds.). (1965). Vakyapadiya of Bhartrahari. Poona: University of Poona.

Adhikary, N. M. (2003, January 13). Communication in Nepali perspective. Space Time Today, p. 4.

Adhikary, N. M. (2003). Hindu awadharanama sanchar prakriya (Unpublished M.A. Thesis). Purvanchal University, Nepal.

Adhikary, N. M. (2004). Hindu-sanchar siddhanta: Ek adhyayan. Baha Journal, 1, 25-43.

Adhikary, N. M. (2007a). Sancharko Hindu awadharanatmak adhyayan. In N. M. Adhikary, Sanchar shodha ra media paryavekshan (pp. 93-138). Kathmandu: Prashanti Pustak Bhandar.

Adhikary, N. M. (2007b). Aristotle's and the sadharanikaran models of communication: A comparative study (Unpublished M.Phil. Independent Study). Pokhara University.

Adhikary, N. M. (2007c). Sancharyoga: Verbal communication as a means for attaining moksha (Unpublished M.Phil. Thesis). Pokhara University, Nepal.

Adhikary, N. M. (2007d). Hindu awadharanama gairashabdik sanchar. In N. M. Adhikary, Sanchar shodha ra media paryavekshan (pp. 139-180). Kathmandu: Prashanti Pustak Bhandar.

Adhikary, N. M. (2008a). Communication, media and journalism: An integrated study. Kathmandu: Prashanti Prakashan.

Adhikary, N. M. (2008b). The sadharanikaran model and Aristotle's model of communication: A comparative study. Bodhi: An Interdisciplinary Journal, 2 (1), 268289.

Bodhi, 3 (1), 69-91. ISSN 2091-0479. (C) 2009 Kathmandu University 
Adhikary, N. M. (2009). Amsanchar ra patrakarita: Sanchar, media ra patrakaritako samasti adhyayan. Kathmandu: Prashanti Prakashan.

Babbili, A. S. (2001). Culture, ethics, and burdens of history: Understanding the communication ethos of India. In S. R. Melkote \& S. Rao (Eds.), Critical issues in communication: Looking inward for answers (pp. 144176). New Delhi: Sage.

Chen, G.-M., \& Miike, Y. (2006). The ferment and future of communication studies in Asia: Chinese and Japanese perspectives. China Media Research, 2(1), 1-12.

Davis, L. (1988). Deep structure and communication. In W. Dissanayake (Ed.), Communication theory: The Asian perspective (pp. 20-38). Singapore: AMIC.

Dhole, V. (2006). Celebrating the incommunicable: The Hindu of social communication. Journal of the Asian Research Center for Religion and Social Communication, 4(1), 27-39.

Dissanayake, W. (1981). Towards Asian theories of communication. Communicator: A Journal of the Indian Institute for Mass Communication, 16(4), 13-18.

Dissanayake, W. (1982a). Personality, transpersonality and impersonality: Some reflections on the relationship of man to nature in three different cultures and its implications for communication theory. Asian Culture Quarterly, 10(1), 26-35.

Dissanayake, W. (1982b). The phenomenology of verbal communication: A classical Indian view. In R. L. Lanigan (Ed.), Semiotics and phenomenology [special issue]. Semiotica, 41(1/4), 207-220.

Dissanayake, W. (1983). Communication in the cultural tradition of India. In M. Traber (Ed.), Philosophical perspectives on communication [special issue]. Media Development, 30(1), 27-30.

Dissanayake, W. (1986). The need for the study of Asian approaches to communication. Media Asia, 13(1), 6-13.

Dissanayake, W. (1987). The guiding image in Indian culture and its implications for communication. In D. L.

Bodhi, 3 (1), 69-91. ISSN 2091-0479. (C) 2009 Kathmandu University 
Kincaid (Ed.), Communication theory: Eastern and Western perspectives (pp. 151-160). San Diego, CA: Academic Press.

Dissanayake, W. (1988a). The need for Asian approaches to communication. In W. Dissanayake (Ed.), Communication theory: The Asian perspective (pp. 119). Singapore: Asian Mass Communication Research and Information Center.

Dissanayake, W. (1988b). Foundations of Indian verbal communication and phenomenology. In W. Dissanayake (Ed.), Communication theory: The Asian perspective (pp. 39-55). Singapore: Asian Mass Communication Research and Information Center.

Dissanayake, W. (2006). Postcolonial theory and Asian communication theory: Toward a creative dialogue. China Media Research, 2(4), 1-8.

Gangal, A., \& Hosterman, C. (1982). Toward an examination of the rhetoric of ancient India. Southern Communication Journal, 47(3), 277-291.

Gordon, R. D. (2007). The Asian communication scholar for the $21^{\text {st }}$ century. China Media Research, 3(4), 50-59.

Gumperz, J. J. (1964). Religion and social communication in village north India. Journal of Asian Studies, 23, 89-97.

Gunaratne, S. A. (1991). Asian approaches to communication theory. Media Development, 38(1), 53-55.

Jain, N. C., \& Matukumalli, A. (1996). The role of silence in India: Implications for intercultural communication research. Education in Asia, 16(2-4), 152-158.

Jayaweera, N. (1988). Some tentative thoughts on communication theory and adwaita vedanta. In $\mathrm{W}$. Dissanayake (Ed.), Communication theory: The Asian perspective (pp. 56-68). Singapore: AMIC.

Khanal, S. (2008). Aamsanchar ra patrakarita. Kathmandu: Vidyarthi Pustak Bhandar.

Kirkwood, W. G. (1987). The turtle spoke, the donkey brayed: Fables about speech and silence in the Panchatantra. Journal of Communication and Religion, 10(2), 1-11.

Bodhi, 3 (1), 69-91. ISSN 2091-0479. (C) 2009 Kathmandu University 
Kirkwood, W. G. (1989). Truthfulness as a standard for speech in ancient India. Southern Communication Journal, 54(3), 213-234.

Kirkwood, W. G. (1990). Shiva's dance at sundown: Implications of Indian aesthetics for poetics and rhetoric. Text and Performance Quarterly, 10(2), 93110.

Kirkwood, W. G. (1997). Indian thought and the intrapersonal consequences of speaking: Implications for ethics in communication. In J. E. Aitken \& L. J. Shedletsky (Eds.), Intrapersonal communication processes (pp. 220-226). Annandale, VA: Speech Communication Association.

Kumar, K. J. (2005a). Hindu perspectives on communication. Journal of the Asian Research Center for Religion and Social Communication, 3(1), 14-20.

Kumar, K. J. (2005b). Indian/Hindu theories of communication. Journal of the Asian Research Center for Religion and Social Communication, 3(2), 90-104.

Majumdar, D. N. (1958). Caste and communication in an Indian village. Bombay: Asia Publishing House.

Masson, J. L., \& Patwardhan, M. V. (1970). Aesthetic rapture: The rasadhyaya of the Natyashastra. Deccan College, Postgraduate and Research Institute.

Miike, Y. (2007). Asian contributions to communication theory: An introduction. China Media Research, 3(4), 1-6.

Miike, Y. (2009). "Cherishing the old to know the new": A bibliography of Asian communication studies. China Media Research, 5(1), 95-103.

Miike, Y., \& Chen, G.-M. (2006). Perspectives on Asian cultures and communication: An updated bibliography. China Media Research, 2(1), 98-106.

Mishra, S. R. (1964). Theory of rasa in Indian drama. Chhatarpur: Vindhyachal Prakashan.

Mohan, P. (1992). In between paradigms: A perspective on communication theory for India. Economic and Political Weekly, 27(15/16), 773-778.

Bodhi, 3 (1), 69-91. ISSN 2091-0479. (C) 2009 Kathmandu University 
Nagar, R. S., \& Joshi, K. L. (2005). Natyasastra of Bharatamuni. 4 vols. Delhi: Parimal Publications.

Oliver, R. T. (1971). Communication and culture in ancient India and China. Syracuse, NY: Syracuse University Press.

Pande, A. (1991). A historical and cultural study of the Natyashastra of Bharata. Kusumanjali.

Pant, L. D. (2009). Introduction to journalism and mass communication. Kathmandu: Vidyarthi Prakashan.

Pant, L. D. (2009, November 24). The Hindu model of communication. The Rising Nepal, p. 4.

Patnaik, T. (1994). Sabda: A study of Bhartrhari's philosophy of language. New Delhi: D. K. Printworld.

Rahim, A. (1987). The practice of antyodaya in agricultural extension communication in India. In D. L. Kincaid (Ed.), Communication theory: Eastern and Western perspectives (pp. 173-182). San Diego, CA: Academic Press.

Saral, T. B. (1983). Hindu philosophy of communication. Communication 8(3). 47-58.

Sastri, G. (1991). Philosophy of Bhartrhari. Delhi: Bharatiya Vidya Prakashan.

Sitaram, K. S. (2004). South Asian theories of speech communication: Origins and applications in ancient, modern, and postmodern times. Human Communication: A Journal of the Pacific and Asian Communication Association, 7(1), 83-101.

Tarlekar, G. H. (1999). Studies in the Natyasastra. Delhi: Motilal Banarsidass Publishers.

Tewari, I. P. (1980, June 1). Sadharanikaran: Indian theory of communication. Indian and Foreign Review, pp. 13-14.

Tewari, I. P. (1992). Indian theory of communication. Communicator: Journal of the Indian Institute of Mass Communication, 27(1), 35-38.

Thirumalai, M. S. (2003, September 9). Understanding nonverbal behavior. Language in India, Vol. 3. Retrieved April 6, 2009 from

Bodhi, 3 (1), 69-91. ISSN 2091-0479. (C) 2009 Kathmandu University 
http://languageinindia.com/sep2003/nonverbalbehavior. html.

Thirumalai, M. S. (2004, July 7). Communication via eye and face in Indian contexts. Language in India, Vol. 4. Retrieved April 7, 2009 from http://languageinindia.com/july2004/eyeandface1.html.

Thirumalai, M. S. (2006, August 8). Communication across castes. Language in India, Vol. 6. Retrieved April 8, 2009 from http://languageinindia.com.

Vatsyayan, K. (1996). Bharata: The Natyashastra. New Delhi: Sahitya Akademi.

Vedantatirtha, N. C. (Gen. Ed.). (1936). Mammata Bhatta's Kavyaprakasa. The Calcutta Sanskrit Series No. VI.

Xiaoge, X. (2000). Asian perspectives in communication: Assessing the search. Retrieved March 14, 2009 from http://www.acjournal.org/holdings/vol3/Iss3/spec1/Xia oge.html

Yadava, J. S. (1979). Communication in an Indian village. In W. C. McCormack \& S. A. Wurm (Eds.), Language and society: Anthropological issues (pp. 627-636). The Hague: Mouton.

Yadava, J. S. (1982, March). Socio-cultural ethos of communication in India. Communication and Culture, pp. 3-4.

Yadava, J. S. (1987). Communication in India: The tenets of sadharanikaran. In D. L. Kincaid (Ed.), Communication theory: Eastern and Western perspectives (pp. 161171). San Diego, CA: Academic Press.

Yadava, J. S. (1998). Communication research in India: Some reflections. In J. S. Yadava and P. Mathur (Eds.), Issues in mass communication: The basic concepts (pp. 177195). New Delhi: IIMC.

Bodhi, 3 (1), 69-91. ISSN 2091-0479. (C) 2009 Kathmandu University 